\title{
A sociological contribution to understanding the use of robots in schools: the Thymio robot
}

\author{
Sabine Kradolfer ${ }^{1}$, Simon Dubois ${ }^{1}$, Fanny Riedo ${ }^{2}$, \\ Francesco Mondada ${ }^{2}$, and Farinaz Fassa ${ }^{1}$ \\ 1 Faculté des sciences sociales et politiques, \\ Université de Lausanne, Switzerland \\ 2 Laboratoire de Systèmes Robotiques, \\ Ecole Polytechnique Fédérale de Lausanne, Switzerland
}

\begin{abstract}
The Thymio II robot was designed to be used by teachers in their classrooms for a wide range of activities and at all levels of the curriculum, from very young children to the end of high school. Although the educationally oriented design of this innovative robot was successful and made it possible to distribute more than 800 Thymio robots in schools with a large majority in the French-speaking part of Switzerland, it was not sufficient to significantly raise the number of teachers using robot technology in their teaching after three years of commercialization. After an introduction and a first section on the design of this educational robot, this paper presents some results of a sociological analysis of the benefits and blockages identified by teachers in using robots, or not, with their pupils.
\end{abstract}

Keywords: educational robot, Thymio II, curriculum, school, sociology

\section{Introduction}

Youngsters find mobile robots fascinating, as some of their features, like movement and interaction with the environment, are similar to those of living beings [1]. Moreover, they have been widely presented in literature, movies and the media as machines that are intelligent and even have feelings (see C-3PO and R2-D2 in the movie Star Wars, for example). But they also have a strong link with the real world because of their various applications, ranging from manufacturing to medicine, from rescue to environmental monitoring.

This wide spectrum of applications allows to use robots in courses on robotics but also in many other robotic-related fields. According to Barreto [2], 80\% of studies on robots in education address fields linked to math or physics. But they can also be used as educational tools for other disciplines, such as geography, history, languages, or the arts. The recent trend to move from STEM (Sciences, Technologies, Engineering and Mathematics) to STEAM (adding an A for Arts) education [3] illustrates this interesting possibility. Moreover, educational robots can be used in formal educational environments such as schools, or in informal education, for instance in festivals or similar outreach events. 
There are few robots widely used in education. Even fewer are designed only for education. Most of them are toys or hobbyist products used for education. One of the best-known robots used in schools is the LEGO Mindstorms, in its various versions, the latest being the EV3. This robot is developed from the famous LEGO bricks, integrating sensors, actuators and a power/computational brick. These additional elements are very classical ones, and the main added value for education comes from the adaptation of the LabVIEW graphical programming environment for programming them. The target market is not only schools, but also the general public, as educational toys. The LEGO Mindstorms is a very flexible tool, making it possible to study programming as well as mechanics, and it can be used to approach robotics and extra-robotic activities. A cheaper version, focused more on the educational market, is the LEGO WeDo kit [4], simpler than the Mindstorms and only allowing one sensor and one actuator to be connected. Also focusing on schools and targeting a low price, TTS produces a robot for primary schools called Bee-Bot [5]. This robot has very simple and classic hardware, making it possible to program a displacement by a sequence of steps and turns of the robot. Also in this case the educational effort has not been focused on the robot hardware, but on the mats on which the robot moves. Such mats make it possible to train abilities that are not directly related to robotics, such as reading, doing simple math, recognizing colors and improving laterality for very young children. While the Bee-Bot looks like a little animal and not a robot, there are a set of kits looking very technical and focused on advanced electronic, mechanical or computer science skills. Those kits can have a visible and modifiable electronics, real mechanical parts such as screws and bolts and classical programming environments based on $\mathrm{C}++$ or Python. The electronics is emphasized in kits based on Arduino [6] or the Raspberry PI boards, for instance. Mechanics is emphasized in kits such as those sold by VEX. In all these kits, the focus of the hardware is on technology and not on educational support. The price of a robot based on this technology is normally above $200 \$$.

There is also a set of educational platforms in the research community that is not spread commercially. We can mention Cubelets[7], Play-i[8], Linkbot[9] or the soft robots by the group of Iida[10]. All these platforms bring to various ages of learners some very interesting concepts developed in robotics research, such as modularity, softness or control concepts, but none digs into the humanrobot interface targeting specifically formal or informal education. We therefore decided to start the multidisciplinary design of an educational platform to be validated by a large usage in the general public and schools.

In this paper, we will first present the principles we considered when designing the Thymio robot for pedagogical use inside classrooms, and then the results of a sociological analysis on the use and acceptance of robots by teachers in classrooms in the French-speaking area of Switzerland (cantons of Geneva and Vaud). The team of Luc Bergeron, Ecole Cantonale d'Art de Lausanne, provided the product design support. The sociological study was carried out by sociologists of the University of Lausanne with the support of the Swiss National Center of Competence in Research "Robotics". 


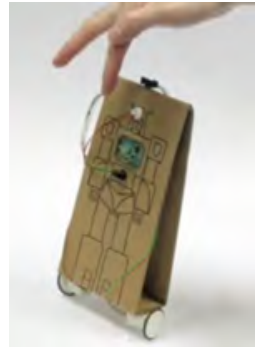

(a) Alive concept (b)

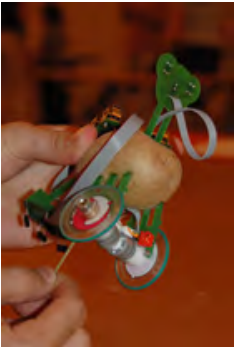

Electronic prototype

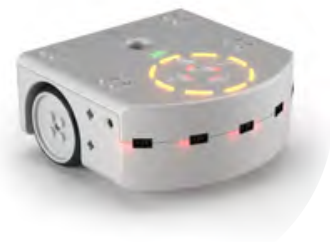

(e) Thymio II

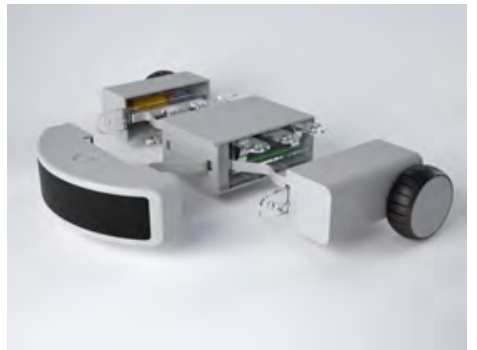

(c) Thymio I prototype

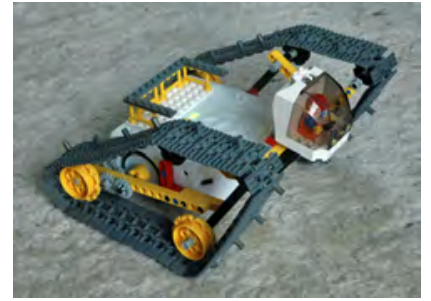

(f) Thymio II use example

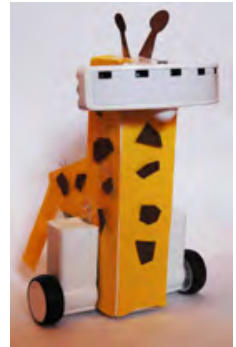

(d) Thymio I use example

Fig. 1: Steps in design from the initial concept (a) to the first working prototype (b) to the first version of Thymio with mechanical modularity (c) and an example of use (d) to the final version of Thymio II (e) and an example of use (f).

\section{The design, from the concept to Thymio II}

The initial concept of this project came from the designers Julien Ayer and Nicolas Le Moigne during a workshop held at the Ecole Cantonale d'Art of Lausanne, Switzerland, in 2010. Their idea was to have sensor and actuator modules to robotize any object, as illustrated in Figure 1a with a cardboard structure. The goal was to enable children to develop their creativity.

This concept has been implemented in some raw prototypes (see figure $1 \mathrm{~b}$ on a potato) that have been tested with children during several workshops. The success of these workshops led us to develop a more finalized version of this system, called Thymio, illustrated in Figure 1c. Figure 1d shows an example of use. The main change between this and the previous concept is that, instead of starting from modules that can be assembled into a robot, which proved to be a difficult task, users start with a working robot that can be disassembled into modules. It is then possible to re-assemble it in new constructions. The appearance was very neutral (white), allowing the children to customize it. The robot had three pre-programmed behaviors. Their respective working principle was illustrated by animated color LEDs. One thousand of these robots were produced and sold at several workshops. This ensured a large set of users that 
could be asked for feedback. Such feedback was collected from 70 families [11] and generated the following improvement suggestions: (i) the existing behaviors were not sufficient, the robot should be programmable, (ii) the users required more sensors and (iii) the users required compatibility with existing construction systems. In parallel we observed that the display of behavior using LEDs was very effective, and that the modularity was not really used.

Based on this experience, we decided to build the actual version of Thymio, called Thymio II. The design principles were the following:

1. The robot should work with pre-programmed behaviors right out of the box.

2. The robot should then be re-programmable by kids.

3. The robot should be modular by allowing extensions. Several mechanical connections were designed on the body and on the wheels.

4. The robot should be as neutral as possible in shape and color to encourage creativity and not to appeal to a specific gender or a specific age.

5 . The robot has been equipped with a much larger number of sensors.

6 . The display of functions and behavior has been strengthened, introducing a specific display for each sensor and a specific color for each behavior.

7. The production price could be increased to support the new functionalities, but still keeping it cheap, i.e. below $45 \$$.

8. The robot should be completely open hardware and software.

These design choices have been complemented by a participative wiki website describing the robot, educational material and videos. More than 5000 robot have been produced and sold worldwide, 800 being in schools. Several training sessions have been organized for teachers in the French-speaking part of Switzerland.

Despite the new design, its effectiveness [12-14] and after three years of dissemination work accomplished in schools, robots, and among them Thymio II, are seldom used in education. This situation was confirmed by our sociological research. As we shall see, according to the informants of the research, this situation is not mainly due to the relevance of robots in education but results from the poor capacity of state subsidized schools to adapt to new technological devices. The same kind of blockages could be observed 25 years ago with the first computers [15] and now applies to tablets. In a period where any expense in education is harshly discussed, these blockages are explained mainly by the financial investment required to introduce new IT devices in schools. Whereas large experimentations should be done to evaluate what education could gain from a regular use of IT and/or robots, the development of IT in education raised intense political debates and were presented as unaffordable for state schools whereas it is not the case in private education [16].

\section{Analysis of diffusion in schools}

A one-year pilot study was carried between August 2013 and July 2014 to better understand how robots are used by teachers in classrooms. We were particularly interested in gathering information on (1) the acceptability of and interest in 
robots as socio-technical educational tools and (2) the resistance and/or acceptance expressed by teachers toward this new type of device. As robots are not common in education and for educational goals, we decided to concentrate our study on the views of the teachers who use robots in education and to investigate more deeply the general disposition to bring such apparatus into the classroom.

We first present the advantages of a wide use of robots in education according to the teachers we met and then describe the kind of blockages they face when they try to integrate robotics into their routine as teachers.

\subsection{Methodology and population}

As the aim of our research was to tackle the benefits and the blockages identified by teachers in using robots with their pupils, we chose a qualitative comprehensive research design which allows the actors' subjectivity to emerge and their good reasons to do what they do to be given. Following the principles of the comprehensive apprehension of social determinants proposed by Max Weber [17] at the beginning of the $20^{\text {th }}$ century and developed since then by numerous sociologists (for more information see [18]), we consider in line with socio-constructivist positioning that an appropriate explanation of a social fact only can be achieved through two preliminary stages: the comprehension and the interpretation of social action as they are given by the actors themselves. The comprehension of the sense and the motivations, in our case for teachers to use robots, was undertaken during the semi-oriented interviews that followed a structured interview guide constructed in line with our research questions. All interviews were recorded and transcribed before undertaking a discourse analysis [19] that isolated the different themes organizing the discourses of the teachers we met in order to highlights shared points of view and therefore to clarify what is at the roots of social actions and in this case at the roots of pedagogical activities and choices. Compared to quantitative methods, which use statistics to identify trends in human actions through deduction, this qualitative approach is inductive. Therefore the opinions and discourses of individuals have an explanatory nature that is central for understanding their actions as the reasons people give to their actions contribute to construct the social realm in which there are enacting [20]. As our informants were mainly (14 out of 15 persons) recruited from the population of teachers that had participated in an event organized by the Laboratoire de Systèmes Robotiques, they all show a particular interest in IT and/or robotics. We tried to get information from people opposed to using robots in classrooms but they were almost impossible to identify. Although our informants regularly stated they were facing reluctance to the introduction of robots by some of their colleagues, they didn't convey us the contacts of such of their colleagues when asked to provide us with their details. Several renditions could be given to this situation : one can consider that the robots interested teachers were unable to cooperate with us because, despite they claiming to face opposition from their colleagues, they were actually isolated, their interest in robotics not being neither shared nor discussed by their colleagues. One can also argue that their reluctant colleagues might not been interested to answer a sociological research 
that raise issues they were opposed to and/or that they didn't wish to give voice to opponents of a deep involvement with this technology such as theirs.

Taking these points into consideration, we nevertheless decided to analyze the discourse of this group of teachers considering it as a specific point of view on robots in education. It is interesting to understand what are the reasons of these committed teachers to introduce robots in education (should it be regular or aimed at children afflicted with cognitive difficulties) and what are the main blockages they say to face when they want to innovate their pedagogical activities thanks to robots. Therefore, the analyses we propose here on the acceptability of robots in education reflect mainly on one hand the understanding of this group of pioneers and on the other the institutional understanding that prevails in the French speaking part of Switzerland, where our research took place.

We carried out 14 interviews with 15 teachers; 7 out of them were men and 8 women, 11 worked in public schools, 3 in private ones and one person was specialized in giving workshops in robotics. They belong to all levels of education, starting with kindergarten (4 year old children) through high school level (18 year old pupils): 8 of our informants work at the pre-primary and the primary level, 2 at the secondary level, 4 at the post compulsory school and 1 who intervenes at different levels. 8 worked either as ICT officer/manager or as PRessMITIC in their schools. This means that this last group of teachers has been specially trained in IT support to help their colleagues or to intervene with pupils on specific topics regarding IT and therefore - sometimes - also robotics. Seven of the 11 users of robots in classroom use Thymio II.

\subsection{Robots and the school curriculum}

The period during which our study was carried out is particularly interesting. The organization of compulsory education has been radically changed since a new educational program for all schools of the French-speaking part of Switzerland "Plan d'études romand" - PER) began to be implemented in 2011/2012. Due to the federalist structure of Switzerland, previously all the regions ("cantons") were independent in their choice of educational policies and curricula. The need to ensure more convergence and more coherence among the different cantons led to an inter-cantonal reorganization of the educational curricula through the PER. This school curriculum does not mention robots directly but one of its topics for the general education of pupils throughout their school years is dedicated to the study of MITIC; PRessMITIC training was created to give support to teachers in these domains. It aims to educate children in ICT and Media tools. Although this domain is not precisely defined, it allows the use of robots for different kind of purposes ranging from raising awareness of technology to a learning of language with the help of robots. This means that the decision to use robots in classes depends mainly upon the teachers' willingness and we could observe that educational robots mainly appear in extracurricular activities such as workshops. 


\subsection{Benefits}

Robots disrupt the traditional teaching styles Robots present great advantages, as several teachers observed, because they disrupt the classical school order, which Vincent et al. [21] call "the scholastic form":

"they [the pupils of a pre-school class] tried them out, they found some of the functions, but not all of them, for example those where had to clap your hands, they never found them, because they were told: "Be careful with it, handle it gently, this equipment has been lent to us," so they never imagined you could touch them to make something happen [she laughs], it goes against a principle we try to teach them from the outset [...] They really liked the fact that they could work on the table and it doesn't fall off, whereas at first they were immediately afraid that it would. They hadn't realized at the start that it wasn't going to fall, so that was a feature they really liked." (101).

The same teacher observed that the benefits of robots for her pupils greatly outweigh the time investment she had to make before being able to start to use robots in her classroom. The break with usual school knowledge was also identified in the application of theoretical knowledge:

"The Thymio robot uses event algorithms, so you have to change their [the pupils'] point of view somewhat, and that's interesting, yes, suddenly you have to... you apply things that you've... that the pupil has learned and then she has to apply it slightly differently. You have to move away a bit from the scholastic application of things, and that's no easy step, but a very useful one if you manage it and especially if you can get the pupils to do it." (106).

Thus, because robots provide new teaching tools, they induce and allow innovative pedagogical practices likely to challenge the dominance of written text as a means of access to knowledge:

"I think it shows them that they understand certain things. But that it isn't math or French. In the class of eleven year olds, who has repeated their year [...] there was a child who went up to his teacher and said, "Today, I feel I'm living again." "(107).

For this very reason, robots are also welcome in working with children who face major difficulties when a normal curriculum is applied:

"And I found that the workshop was a good way to bring together pupils who were performing poorly but who had real abilities, others who found it hard to conceptualize things, math and even physics and chemistry, they can be very abstract sometimes, and pupils who weren't integrated, and so I ran that workshop for pupils aged 11 to 15. I was a bit worried about the age difference, but I wanted to try out a kind of... group spirit." (102).

Although robots may help children to understand concretely what they are doing and enable them to progress, they also break with theoretical knowledge and 
traditional teaching styles that are based on the practice of written language according to the work of Vincent et al. [21]. In line with their findings, we can conclude that in so doing, robots are also likely to destabilize the balance of power that formal education reproduces according to Bourdieu [22].

Which robots for which children? In our interviews, we could identify that different robots are used at different ages. Although Thymio II was designed for types of pupils from pre-school classes up to university, it is often integrated into education after an introduction to BeeBots (from the first to the sixth school year for children aged 4 to 10 and before or in parallel with the Arduino and the Lego Mindstorms, which are mostly used in senior high school (pupils aged 15 and over). One of our interviewees considered that:

"for the youngest, Beebot is almost better [than Thymio II], because they can really control the movements" (101),

and another one saw Thymio as useful for an introduction:

"As I see it, at whatever age, from 11 to 18, even if they of course don't approach it in the same way, Thymio is an introduction to robotics. It's... a way in. It seems to me to be the simplest." (102).

Two different types of practice were described by the teachers we met: robots can be used either (1) as tools to enhance various types of learning (including languages), or (2) as technical devices to study robotics and the disciplines that are at its roots (computer science, math, physics, electronics, etc.). Activities in the first category are mainly mentioned in primary schooling. For these pupils, there are linked to spatial awareness, which can easily be done with BeeBot or Thymio II:

"I think that with children who have a lot of problems with spatial orientation you could... yes, stimulate them by getting the robot to move around, follow a route [...]. And they could say "Now I'm upside down, now I'm the right way up". Starting from an early age. I think that would help them a lot." (111).

A seminal workshop to learn German is often cited as an example that could be followed to use robots in an innovative way at the secondary level, but apart from the teacher who developed this lesson, very few people seem to have endorsed it.

We nevertheless observed a situation in which these devices are very seldom present in the classrooms: between the use of robots with youngsters in primary school and their use in post-compulsory education. The reasons for this are complex and they relate in good part to the school curriculum in secondary classes and to the school organization.

"There's the world of infants' and primary schooling, where the teacher is in practice relatively free to choose what he does, the activities, and there, working with Thymio is great. And then you enter the world of the secondary school, where the French teacher is there to do French dictations and spelling and then comes the math teacher who has to do math theorems, and... and... there's not much room for robots, unless you create specific options." (105). 


\subsection{Blockages}

As the PER does not explicitly mention robots, even where teachers work in subjects related to robotics, they have to face barriers to their proper use.

Money The main difficulty stems from the fact that robots are still an expensive technology. The high cost of Lego Mindstorms was often mentioned by our interviewees, but even with less expensive products such as Thymio II, the question of very limited school budgets appears to be central:

"We are told, "Oscilloscopes are a good thing," because there's an official text that says that every school teaching for that qualification must have an oscilloscope. No room for argument there. You go to the principal and say "It's not my idea, it says so there." But it doesn't say that every school must have a robot." (105).

or

"I had to beg for funds... I bought two [Thymio] robots at the robotics fair, with my own money. And then I asked if it might be possible to reimburse me, and that was allowed, and then I asked if I could buy two more." (111)

And as the same interviewee explains a little later, even when she was allowed the money to buy robots, she finds it difficult to order them. She told us how a colleague was interested in using robots with his pupils and he asked her to order them, but she could not do so:

"That colleague could help me make the missing link for those who would like to do some robotics in the school. And then you come up against the CADEV catalogue (the central purchasing department of the State of Vaud), which doesn't offer everything! [...] So I phone Mr. X. and say, "You see, X, my colleague $\mathrm{Y}$ wants to do some robotics and he's familiar with the Raspberry Pi: what did you do to order them for your school, because I can't get them through that CADEV catalogue?" " (111).

Private schools are in a rather better situation in that regard. Although they seem more open to working with robots on pedagogical grounds, financial questions also play a large role. In contrast to the subsidized state schools, using robots in private education can even be viewed as a means to generate a benefit for everyone. Although the optional workshops offered to the pupils (on computer science) require an additional payment from the parents, the cost they entail are no longer a barrier and this innovation can be brought into the school as a useful extra educational contribution to the children's future:

"This is a private school, no problem there, the parents are very interested, the principal is very interested, he bills it as an extra at... incredible prices for the parents. The parents are happy, I'm happy, and the kids are happy because they each have their robot. That's not the problem. It's more a question of: "But what place does that have in a lesson?" " (102). 
Time, training and curriculum The current poor integration of robots into education has the consequence that teachers don't view the immediate utility of robots and that they approach activities with this socio-technical device as particularly time-consuming. While the most convinced among them overcome this difficulty, it may create barriers for the beginner. Due to the lack of time to invest in creating pedagogical sequences including robots, they wish to get ideas and ready for use instructions to carry out a proper lesson.

"If we really wanted to develop good material for the Thymios, we'd need a great amount of time, and some reduction in our teaching load to do it. [...]

But given the duties assigned to me, I can't really do it." (111)

Robots in classrooms being a pioneers' activity, the pedagogical equipment is not clearly identified, even if teachers working with Lego Mindstorms did not mention it as often as the ones who explore Thymio II. So setting up activities with robots is seen as time-consuming, and teachers sometimes feel lonely in this odyssey:

"I'm all alone in this [...]. I set up the workshop on my own. Defining the educational aims and objectives was all down to me, sorting out software bugs in the evening or early morning, running the workshop, all that is my work. I have no team, no support, and in particular no colleagues who are interested."

Finally, even when teachers are interested in using robots, either because they know robots from previous experiments outside school with this kind of device, or, having attended a workshop offered by the HEP-VD or robot specialists from the EPFL, they might be willing to introduce robots into their teaching activities, they are confronted to budget constraints. But they also have to face difficulties due to the fact that the school curriculum does not really allow them to teach this kind of knowledge:

"So I wanted to run a robotics course [but due to the curriculum spelling] I realized I couldn't then integrate it into my lessons, whether in math, or physics and chemistry, or electricity, which are the subjects I am spread over [...]. I had to call it a workshop [i.e. optional], because I wasn't allowed to call it a lesson (laughs)." (102).

\section{Conclusion: Using robots in classrooms without institutional injunctions?}

The Thymio project was started to bring technology education to a large number of youngsters. We started this project with mechatronics, product and interaction design, targeting the best learning experience, and we had considerable success in three years of informal education events. In formal education (schools) Thymio achieved a similar acceptance and diffusion to those of other tools such 
as the BeeBot or Mindstorms robots, which have fewer education-oriented technical features, are not open-source, have fewer sensors and are not gender or age neutral. After three years of sales and with more than 800 Thymios being mainly used in Swiss schools, the sociological study presented enables to better understand the perceived benefits but also the factors blocking a wider diffusion.

Among the broader benefits, it has been observed that robots such as Thymio break with the classical school order and can facilitate the education of children who face difficulties when following a normal curriculum. This social aspect of the use of robots was observed in several teaching disciplines.

The observed blocking factors often come from the school structure. Although money can be a problem and Thymio brings a solution with its lower price and broad use across ages, this is not the only problem. The lack of injunctions in favor of robotics in educational policies or from local authorities (school area directors) is also at the basis of a lack of pedagogical research on the benefits that robots could offer to education. Therefore, working with these devices implies a commitment that is difficult to fulfill for regular teachers. Not having a proper training and not having activities at hand that they can offer to their pupils, planning activities with robots seems so time-consuming that a great proportion of them give up before trying.

Therefore it is crucial to better spread knowledge on the possible benefits of using robots in education and to develop research on that field [23]. This requires a real backing from educational policies and a larger involvement of entities that are in charge of teacher training or are references in the use of technology. We have already tested, for one year, the organization of regular training sessions for teachers, with a big attendance despite the fact that the sessions were during the teachers' free time. We will continue this effort and are starting to develop ready-to-use material fitting the standard school programs in math, science and other disciplines.

To conclude, introducing a robot into the educational ecosystem of a school requires a strong interdisciplinary effort involving technology, sociology, pedagogy and politics. We hope that this study will encourage other interdisciplinary efforts in this critical domain.

\section{Acknowledgments}

This research was supported by the Swiss National Center of Competence in Research "Robotics".

\section{References}

1. S. Turkle, The Second Self. Simon and Schuster New York, 1984.

2. F. B. V. Benitti, "Exploring the educational potential of robotics in schools: A systematic review," Computers E Education, vol. 58, no. 3, pp. 978-988, 2012.

3. Y.-G. Jin, L. Chong, and H.-K. Cho, "Designing a robotics-enhanced learning content for steam education," in Ubiquitous Robots and Ambient Intelligence (URAI), 2012 9th International Conference on, pp. 433-436, Nov 2012. 
4. LEGO, "Lego wedo." http://www.legoeducation.us/eng/categories/products/elementary/legoeducation-wedo, 2013.

5. TTS Group, "Bee-Bot." http://www.beebot.org.uk, 2011.

6. R. Balogh, "Educational robotic platform based on arduino," in Proceedings of the 1st international conference on Robotics in Education, RiE2010. FEI STU, Slovakia, pp. 119-122, 2010.

7. M. D. Gross and C. Veitch, "Beyond top down: Designing with cubelets," Tecnologias, Sociedade e Conhecimento, vol. 1, no. 1, pp. 150-164, 2013.

8. Play-i, "Play-i: Delightful robots for children to program." https://www.playi.com, 2014.

9. Barobo, "Barobo, inc. - educational robotics." http://www.barobo.com, 2014.

10. X. Yu, D. Assaf, L. Wang, and F. Iida, "Robotics education: A case study in softbodied locomotion," in Advanced Robotics and its Social Impacts (ARSO), 2013 IEEE Workshop on, pp. 194-199, Nov 2013.

11. F. Riedo, P. Rétornaz, L. Bergeron, N. Nyffeler, and F. Mondada, "A two years informal learning experience using the thymio robot," in Advances in Autonomous Mini Robots, pp. 37-48, Springer, 2012.

12. S. Magnenat, J. Shin, F. Riedo, R. Siegwart, and M. Ben-ari, "Teaching a Core CS Concept through Robotics," in 19th Annual Conference on Innovation and Technology in Computer Science Education (ITiCSE), 2014.

13. S. Magnenat, F. Riedo, M. Bonani, and F. Mondada, "A Programming Workshop using the Robot "thymio ii": The Effect on the Understanding by Children," in Proceedings of the IEEE International Workshop on Advanced Robotics and its Social Impacts, pp. 24-29, IEEE, 2012.

14. F. Riedo, M. S. D. Chevalier, S. Magnenat, and F. Mondada, "Thymio II, a robot that grows wiser with children," in Advanced Robotics and its Social Impacts (ARSO), 2013 IEEE Workshop on, pp. 187 - 193, IEEE, 2013.

15. F. Fassa, Société en mutation, école en transformation : le récit des ordinateurs. Éd. Payot, Lausanne, Switzerland, 2005.

16. L. Burgeois, "Une cole vaudoise mise sur la tablette," 24 Heures, December 2nd, 2013.

17. M. Weber, From Max Weber: essays in sociology. Routledge, 2009.

18. J.-C. Kaufmann, L'entretien compréhensif. Armand Colin, 2011.

19. S. Beaud, "L'usage de l'entretien en sciences sociales. plaidoyer pour l' "entretien ethnographique"," Politix, vol. 9, no. 35, pp. 226-257, 1996.

20. P. L. Berger and T. Luckmann, The Social Construction of Reality. New York: Doubleday, 1966.

21. G. Vincent, L'éducation prisonnière de la forme scolaire? Scolarisation et socialisation dans les sociétés industrielles. Presses Universitaires, Lyon, 1994.

22. P. Bourdieu and J. C. Passeron, Reproduction in Education, Society and Culture, vol. 4. Sage, 1990.

23. J. Han and D. Kim, "r-learning services for elementary school students with a teaching assistant robot," in Human-Robot Interaction (HRI), 2009 4th ACM/IEEE International Conference on, pp. 255-256, IEEE, 2009. 